\title{
Anti-smog regulations in Poland as a case study of the effectiveness of law
}

\author{
Mateusz Klinowski, Mateusz Stępień, \\ Jagiellonian University - Kraków, Poland
}

\section{Introductory remarks}

Environmental issues are currently among the most discussed topics in politics all over the world. In Poland, however, the issue of air quality has become one of the most publicly debated topics only in recent years. Although even in 2014 air pollution was still largely ignored by mainstream politics, the rise of the civic movement focused on the issue has quickly changed the mindset of politicians. The foundation of Krakow Smog Alarm in 2013 - a nongovernmental organization pooling civic activists and independent experts concerned by the level of pollution in one of the oldest cities in Poland, and the vocal social campaigns that followed, should be considered as the turning point. Never have activists in Poland challenged politicians in power over the environmental issue with such vast support of the general public and media.

It is important to note that the level of air pollution in Poland is one of the highest in Europe in respect of particulate matter (PM). Only some other, usually much poorer, East European countries indicate similar levels of pollution.' In turn, the region of Lesser Poland, with the city of Krakow as its capital, is one of the two (the other is Upper Silesia) most affected regions. ${ }^{2}$ According to data published by WHO, out of 50 cities with the highest concentration of PM2,5 in

1 EEA Report No 10/2019, Published 16 Oct 2019, pp. 26-33, doi:10.2800/822355, https://www.eea.europa.eu/publications/air-quality-in-europe-2019

${ }^{2}$ See Jakość powietrza w Polsce w roku 2018 w świetle wyników pomiarów prowadzonych w ramach Państwowego Monitoringu Środowiska [Air quality in Poland in 2018 in the light of the results of measurements carried out by the State Environmental Monitoring], Main Environment Protection Inspectorate, pp.100-129 - available at http://powietrze.gios.gov.pl/pip/content/measuring_air_assessment_rating_info 
ULP Law Review | Revista de Direito da ULP

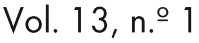

doi: 10.46294/ulplr13n1 ga2

the EU, as many as 33 are located in Poland, mostly located in the regions of Upper Silesia and the Lesser Poland. ${ }^{3}$ Also, reliable scientific data show that the major source of particulate matter in the atmospheric air are households' heating systems fueled by coal and wood. It is estimated that so-called low emission - as opposed to emission $40 \mathrm{~m}$ above the ground level, usually being a byproduct of industrial activity - is responsible for $46.5 \%$ of particulate matter measured in the air. In fact, only $26 \%$ of the total PM10 emission is due to the industrial sector of the economy, while its share in measured air pollution is considerably lower, due to the spatial separation industrial zones are concentrated and far from residential ones and particulate matter is emitted higher in the atmosphere. ${ }^{4}$

Krakow is especially affected by air pollution. It is in a highly populated area, being a center of agglomeration, with high concentration of single-family houses typically heated by coal fueled furnaces. Krakow is also a popular tourist destination and the quality of air started to influence its international brand, what became an important argument in the debate. ${ }^{5}$ No wonder then, that in reaction to the campaigns of Krakow Smog Alarmand the rising public awareness, the regional parliament of the Lesser Poland, as well as the municipal authorities, decided to take action.

In 2015-2017, several legislative attempts were undertaken, with strong support of local activists and media, aimed at limiting the combustion of solid fuel in the city of Krakow as well as in the whole region of Lesser Poland. Finally, by resolutions of the 15th of January 2016 and the 23rd of January 2017, the local parliament of Lesser Poland introduced restrictions on the use of solid fuel in heating installations in the area of the Municipality of Krakow and the rest of the province, respectively. ${ }^{6}$ Restrictions consisted in the regulation of the permissible types of fuel and installations for use in individual households. The first resolution, dedicated to the area of Krakow,

\footnotetext{
3 See: WHO Global Urban Ambient Air Pollution Database (update 2016) https://www.who.int/phe/health_topics/outdoorair/databases/cities/en/

${ }^{4}$ See Jakość powietrza w Polsce... op. cit., p. 134.

${ }^{5}$ At the time when the air pollution debate started the city received The Best European City Trip 2015 award by Zoover, one of Europe's leading travel websites, beating other well-known tourist destinations such as Venice, Barcelona, Prague or Rome.

${ }^{6}$ According to the article 96.1 of the Act of 27 April 2001 Environmental law (Dz.U. $2001 \mathrm{nr} 62$ poz. 627) it is prerogative of the regional parliament to restrict or prohibit the use of any installations combusting solid fuel.
} 
ULP Law Review | Revista de Direito da ULP

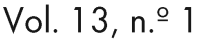

doi: 10.46294/ulplr13n1 ga2

proposed a very short deadline for implementing a total ban on solid fuel (with the deadline in September 2019), while maintaining high subsidies for a replacement of installations (in some periods up to 100\% of the investment value), financed mostly by the city budget and EU funds. In turn, the second resolution regarding the remaining area of Lesser Poland, focused on the voluntary, incentive-based gradual replacement of furnaces, with a long adjustment period (in case of some type of installations even until 2026) and with relatively little financial support from the state or local governments (30-50\% of the investment value). Generally, these resolutions corresponded to the two different philosophies or strategies for solving societal problems described in the literature - the strategy that relies on command and control and the strategy that relies on economic incentives. ${ }^{?}$

This poses a couple of questions. First, why two separate strategies were adopted instead of one? What kind of arguments do stand for any of them? And more profoundly, are both strategies similarly effective in reducing air pollution or one of them is more effective than the other? These questions seem to be even more important as soon as we realize that the preparation of both resolutions was preceded by the preparation of the scientific study of the actual distribution of air pollution in the province and mathematical modeling of the future distribution of pollutants after the implementation of regulations (with the use of the CALPUFF modeling system). ${ }^{8}$ Thus, a preemptive assessment of the effectiveness of introduced regulations based on scientific evidence (including actual measurements and mathematical modeling) was made and it was thereafter used to justify both of the resolutions. It is interesting to note that the study clearly stated that the regulation of 2017 would not result in a full resolution of the problem of air pollution in the region of Lesser Poland, while indicating the total ban of solid fuel, introduced only for the city of Krakow by the resolution of 2016, as an effective tool. This observation leads to the conclusion that while

\footnotetext{
${ }^{7}$ See Bates, R. et al. (1994) Alternative Policies for the Control of Air Pollution in Poland. Washington: The World Bank.

${ }^{8}$ See: Air Protection Program for the Province of Lesser Poland - Resolution No. XXXII/451/17 Regional Assembly of the Lesser Poland of January 23, 2017, available at http://edziennik.malopolska.uw.gov.pl/WDU_K/2017/811/akt.pdf
} 
ULP Law Review | Revista de Direito da ULP

Vol. 13, n. $\stackrel{1}{1}$

doi: 10.46294/ulplr13n1 ga2

described legislation poses to be a case for evidence-based policy, some other factors than scientific evidence played the central role in determining the final shape of passed laws.

All of this creates a unique occasion for researching social policies in the making as well as for developing some theories in the field of policy science. Below we provide a sketch of such a research aiming at invigorating discussions regarding effective strategies for dealing with hard societal problems.

\section{The case study of anti-smog resolutions in Lesser Poland}

Our idea consists of, in the first place, a case study of the policies (represented by two separate regulatory regimes) aimed to improve air quality in Lesser Poland. In this context a case study perspective seems to be a quite natural candidate for a research framework. In a typical case study the subject of research is limited to a well-defined area to achieve in-depth and multifaceted view on the researched matter. Employment of many diverse sources of information and research techniques are required, dependent on the complexity of the case. A case study heads toward obtaining relatively undistorted knowledge by observing its subject directly, "in action" and with as little as possible of prior conceptualization. ${ }^{9}$ In turn, so-called comparative case study can be implemented in cases when very similar subjects of study differ in respect of some fundamental features. In our opinion the case of Lesser Poland gives the opportunity to conduct such a comparative case study, where the processes of creation, implementation and functioning of two different regulatory regimes can be directly compared. ${ }^{10}$

At the first glance our idea of a case study of two resolutions of 2016 and 2017 doesn't seem to be especially groundbreaking. Usually in a case of legal regulations a study is limited to source materials: official justifications, reports and other documents commissioned by the legislative

\footnotetext{
${ }^{9}$ On a comprehensive discussion of the case study methodology see: Gerring. J. (2007) Case Study Research: Principles and Practices. Cambridge: Cambridge University Press.

${ }^{10}$ On various types of comparative case study see: Bartlett, L. \& Vavrus, F. (2017) Rethinking case study research: a comparative approach. New York: Routledge.
} 
ULP Law Review | Revista de Direito da ULP

Vol. 13, n. $\stackrel{1}{1}$

doi: 10.46294/ulplr13n1 ga2

body, transcripts of meetings, positions voiced by social actors or signaled during consultations and so on. The other usual subject of analysis is the public communication regarding the regulation, which include a content of possible communication campaigns (leaflets, banners, messages) and media publications. As for an effect of such a study, for example, usually one describes and systematizes legal, economic and moral arguments formulated during the public debate in the process of legislation.

As mentioned earlier, in the respect of the anti-smog policy in Lesser Poland, it seems to be crucial to determine factors ultimately shaped the content of the resolutions and the relations of these factors to the preexisting expert knowledge. If environmental policies in Lesser Poland haven't been determined by scientific evidence, it could be very illuminating to figure out the actual reasons behind their adoption in every case. We even anticipate that both legislative processes were characterized by different intensity of specific types of arguments, thanks to a different treatment of the same expert opinions and knowledge. Also, the process of communicating the content of adapted regulations, which took place after the legislation was passed, differs. It is important to analyze the methods of social communication employed in the case of both anti-smog resolutions and reconstruct all the mechanisms used to communicate the new resolutions, beyond its sheer publication. We have a hunch that multi-level communication was adopted in the case of the resolution concerning the city of Krakow, whereas uncoordinated and less concentrated measures were taken in the case of the second resolution concerning the remaining area of Lesser Poland.

However, our ultimate goal is not limited only to examining written material in order to eventually uncover relevant factors responsible for the legislation which, despite appearances, turned out to be not based on scientific evidence. Rather, we would like to gain valuable insight into the structure and rationality of official institutions that stood behind and supported both resolutions, in order to add a new dimension to a widely discussed theory in the field of policy science (more on this later). 
Anyway, in the case of law the most interesting thing, in the first place, is its actual effectiveness. And it seems that the situation we encounter in Lesser Poland creates an unique opportunity also to explore this issue - both empirically and conceptually.

\section{The question of effectiveness of law}

The effectiveness of law is one of the classic themes in jurisprudence. In Polish theory of law, several authors characterized different types of the effectiveness ascribed to the law. For example, according to the classic work of Wróblewski these types include psychological, behavioral, finest and educational effectiveness." In turn, according to Koider one can single out the effectiveness of establishing, announcing, applying and binding of law, ${ }^{12}$ while Wronkowska proposes to think rather about formal, real and motivational effectiveness. ${ }^{13}$ Finally, Kowalski, Lamentowicz, and Winczorek propose the categories of formal, material and axiological effectiveness. ${ }^{14}$ As we see, the existing literature on effectiveness, at least in Poland, is focused on the conceptualization and systematization of various types of "effectiveness" with much less attention for empirical research of any particular regulation. ${ }^{15}$ Also, it is worth to note that, as far as we know, the case study research framework has not been applied yet directly to the problem of the effectiveness of particular regulations, although the case study methodology was of course used to conduct some empirical research within the realm of law. ${ }^{16}$

\footnotetext{
"See Wróblewski. J. (1980) Skuteczność prawa i problemy jej badania [The Effectiveness of the Law and the Problems Associated With Its Research]. Studia Prawnicze: 1-2.

${ }^{12}$ See Kojder, A. (2009) Ograniczenia skuteczności prawa [The Limits of the Effectiveness of Law]. [in:] Skuteczność prawa. Konferencja Wydziału Prawa i Administracii Uniwersytetu Warszawskiego.

${ }^{13}$ See Wronkowska, S. (2001) Kryteria oceny prawa [Criteria for Assessing the Law]. [in:] E. Kustra (ed.) Przemiany polskiego prawa [Changes in Polish Law], Toruń.

${ }^{14}$ See Kowalski, J. et al. (1981) Teoria państwa i prawa [Theory of State and Law], Warszawa: PWN.

${ }^{15}$ Perhaps the only exception are studies conducted by A. Stelmachowski - for a summary of this research see Zdziennicki, J. (2009) Przyczynek do zaimowania się skutecznościa prawa na WPiA UW[A Contribution to Dealing with the Effectiveness of Law at the WPiA UW]. [in:] T. Giaro (ed.), Skuteczność prawa. Konferencja Wydziału Prawa i Administracii Uniwersytetu Warszawskiego, 27 lutego 2009 r. [The Effectiveness of the Law. Conference in the Faculty of Law and Administration of the University of Warsaw, 27 February 2009], Warszawa.

${ }^{16}$ See e.g. Leeuw, F., Schmeets H. (2016) Empirical Legal Research: A Guidance for Lawyers, Legislators and Regulators. Cheltenham, UK: Edward Elgar Publishing Limited, pp. 112-114 or Webley, L. (2016) Stumbling Blocks
} 
Let's now turn to the major idea behind our research on the anti-smog regulations of 2016 and 2017 in Lesser Poland. We assume that the existence of both resolutions creates an unique opportunity to measure directly and with mathematical precision the impact of two different sets of regulations corresponding to the two different philosophies of dealing with societal problems, briefly characterized above as command and control and economic incentives regimes. This measurement can be conducted due to the presence of the network of certified sensors owned by the Environmental Protection Inspectorate (a governmental institution), which are distributed in the whole region. That network is complemented by even more dense commercial networks, continuously measuring the air quality in Lesser Poland. Those are less sophisticated sensors yet working with reasonable accuracy. The existing networks of sensors give an apparent possibility of objectively determining the quality of air condition in Lesser Poland day by day. Hence, by collecting publicly accessible and reliable data sourced by continuous measurement in both areas of regulation (the city of Krakow and the rest of Lesser Poland) before and after the legislation, we should be able to determine the relation between the adopted regulations and the measured level of pollution. So, objective, precise and abundant data can be employed to determine the apparent causal results of adopted regulatory regimes and policies. This may be interpreted, provisionally, as the closest estimation of measuring the practical effectiveness of actual laws, i.e. two versions of anti-smog resolutions passed in Lesser Poland in 2016 and 2017.

Our preliminary assessment leads to the conclusion that the resolution of 2016 is effective and leads to a visible reduction of air pollution in the city of Krakow, while the resolution of 2017 remains ineffective and has no measured influence on the quality of air in the remaining area of Lesser Poland. Of course, the sheer data is just a first step to more advanced considerations regarding the actual effectiveness of both resolutions, where different concepts of effectiveness must be discussed as well as various difficulties associated with determining causal relationships in general and the case of air pollution in particular. A convincing justification is needed for holding

in Empirical Legal Research: Case Study Research. Law and Method 3: pp. 1-21, or Argyrou, A. (2017) Making the Case for Case Studies in Empirical Legal Research. Utrecht Law Review3: pp. 95-113. 
ULP Law Review | Revista de Direito da ULP

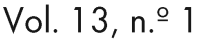

doi: 10.46294/ulplr13n1 ga2

that the dynamics of changes in the air condition in the area of regulation of two different antismog resolutions depends mainly on the content of resolutions, and not on other independent factors.

We need not only to gather and interpret the data, but also convincingly justify the relationship between a particular regulation and measurement. At the first glance, such a relationship could be distorted by the propagation of air pollution from one area of regulation to another. We must also identify the unintended consequences of two anti-pollution regimes. ${ }^{17}$ It could be especially important in the case of explaining the apparent ineffectiveness of the resolution of 2017. Before we come to any general conclusion about the usefulness of one type of regulation as opposed to another (i.e. the command and control regime as opposed to the economic incentives regime) we must be sure that there is no any collateral causal influence. For instance, the strategy of command and control was employed in Krakow by a single authority (local government with a huge budget) while the economic incentives model is implemented in the remaining region of Lesser Poland by many local governments with tighter budgetary restrictions. Hence, the apparent opposition between one body / huge budget and many bodies / small budgets must be taken into consideration as one of the factors potentially influencing the "final" effectiveness of both resolutions and thus both types of regulations. It is extremely important to estimate if and to what extent this and other similar factors must be accounted for in order to directly "measure" the effectiveness of law, as we plan in the case of the anti-smog resolutions.

\section{The natural experiment in Lesser Poland}

The specific situation that occurred on the territory of Lesser Poland as the result of the introduction of the resolutions of 2016 and 2017 may be viewed as a kind of natural experiment,

\footnotetext{
${ }^{17}$ The literature on the theoretical issue of unintended consequences of interventions is rather abundant, starting with the classic work of R. Merton, see: Merton R. K. (1936) The Unanticipated Consequences of Purposive Social Action. American Sociological Review 1(6): 894-904.
} 
ULP Law Review | Revista de Direito da ULP

Vol. 13, n. $\stackrel{1}{1}$

doi: 10.46294/ulplr13n1ga2

which provides us with the unique possibility of an in-depth empirical analysis of the circumstances, conditions and limitations associated with political, legal and social interventions, in this case aiming at improving air quality. ${ }^{18}$ The uniqueness of the situation is characterized by the combination of the following circumstances: (1) the occurrence of two opposing regulatory regimes (policies), (2) which are spatially, but not temporally separated, (3) well-defined objectives of both regimes which should allow, at least in principle, for an easy estimation of their effectiveness, (4) by direct comparison of two available sets of measurements. It is worth noting that this allows a direct comparison of the effectiveness not only of the two specific legal regulations, but also of the two broader general strategies or policies, or philosophies (command and control vs economic incentives) of dealing with societal problems, which the both resolutions represent.

Thanks to the abundance of existing data, including official documents and expert opinions on the subject, produced during the process of legislation, and the presence of a specialized professional group (so-called eco-advisers), whose members have comprehensive knowledge about the implementation of both resolutions, as well as the existence of the organized community of local anti-smog activists from the NGO sector, we can extend our research even further and try to grasp the effectiveness of the regulations in question as a function of various underlying assumptions and presuppositions. Thus, we plan not to limit our study on effectiveness to mere comparison of measurements, but also conduct qualitative research using in-depth interviews targeting groups of individuals involved in the process of implementing the resolutions of 2016 and 2017 in Lesser Poland. Among stakeholders relevant for the process we identify officials working at the Marshal's Office of Lesser Poland and the Municipality of Krakow, representatives of non-governmental organizations involved in taming air pollution (eg. Polish Smog Alarm with its 13 local branches) and a representative sample of the mentioned eco-advisers, working for Lesser Poland municipalities of various sizes.

\footnotetext{
${ }^{18}$ For the detailed account of the natural experiment approach see Dunning, T. (2012) Natural Experiments in the Social Sciences: A Design-Based Approach. Cambridge: Cambridge University Press.
} 
The latter group is constituted by about 60 people implementing the project entitled "LIFE Lesser Poland in a healthy atmosphere" - dedicated to the task of efficient implementation of anti-smog policies in Lesser Poland. Eco-advisers are local government employees, partly financed from EU funds, whose task is an environmental education, coordination of anti-smog policies at the level of municipalities participating in the program, and providing assistance to residents in access to external financing for the replacement of heating installations. Hence, eco-advisers have vast knowledge about local determinants affecting the effectiveness of anti-smog regulations. The research sample group will be determined randomly, ensuring the most complete representation for municipalities of all sizes (random selection within each type of municipalities). Just to give readers a glimpse, in Lesser Poland alone there is a total sum of 182 municipalities, including 14 urban, 48 urban-rural, 120 rural and 3 big cities with poviat rights.

Conclusions from the interviews are supposed to reveal the complex background of the process of passing both resolutions, communication of their content and reconstruction of their real effects. We believe that the individuals selected for interviews will have information necessary to figure out which arguments were used and, even more importantly, which were omitted during the legislation process, and how the process of implementing both resolutions did look like. Of course, such a plan of research is associated with certain risks. The willingness of selected individuals to participate in the research and openly express their views, especially on responsibility for the effectiveness of implemented policies, must be accounted for. In case of decision-makers and representatives of authorities, these people have repeatedly expressed their positions in the public debate, so we may assume in advance the willingness to participate in the study. The selection of decision-makers representing various sides of the political dispute and levels of administration should ensure that even basing on partially dishonest statements we will get a fairly objective picture of the situation. As for the group of eco-advisers, the same factors will come into play although they kind of represent a local administration, they are not associated with any specific political option, and the nature of their work consists in public communication of anti-smog 
policies. As far as NGOs are concerned, we do not expect the occurrence of above-mentioned risks due to the nature of these entities and the objectives of their mission.

Our research project will also be supplemented by the analysis of existing data in the form of studies on the attitudes of the inhabitants of Lesser Poland toward environmental issues, as well as toward the content of both resolutions that were passed by the local parliament. Such data is currently available, so there is no need to conduct our own, expensive and time-consuming research on legal awareness in these particular areas. ${ }^{19}$

It is also worth noting the innovative character of our study. The literature on air conservation and pollution in Poland has focused so far mainly on the health consequences of air pollution. Krakow was often taken as the reference point because of the measured high levels of pollution to which the probability of health risks - primarily lung cancer ${ }^{20}$ or threats to the health of pregnancy and infants ${ }^{21}$ was referred. The international study on the relationship between the development of children's cognitive abilities and the exposure to air pollution, part of which was a study carried out in Krakow, also gained considerable publicity. ${ }^{22}$ In contrast to that, our research does not deal with the issue of causal relationships between health consequences and smog, it also doesn't aim at the economic analysis of various types (incentives / bans) of policies dealing with air pollution. On the contrary, we aim to assess the real, measurable effects of the actual policies in the first place, in order to pinpoint the most effective strategy.

\footnotetext{
${ }^{19}$ See: Air quality in the assessment of the inhabitants of the Małopolska region. The research report, CEM Institute for Market and Public Opinion Research, Krakow, September 2016, and Air Quality in the assessment of residents of the Małopolska region. Research report, CEM Institute for Market and Public Opinion Research, Krakow, May 2018, and A. Dworakowska, A. Guła, Ł. Pytliński, Evaluation of programs supporting coal boiler replacement and thermomodernization of single-family houses, Institute of Environmental Economics, Krakow 2019.

${ }^{20}$ Jędrychowski, W. et al. (1990), A Case-Control Study of Lung Cancer with Special Reference to the Effect of Air Pollution in Poland. Journal of Epidemiology \& Community Health 44: pp. 114-120.

${ }^{21}$ Whyatt, R. M. et. al (1998) Relationship Between Ambient Air Pollution and DNA Damage in Polish Mothers and Newborns. Environ Health Perspect3: pp. 821-826.

${ }^{22}$ Edwards, C. et al. (2010) Prenatal exposure to airborne polycyclic aromatic hydrocarbons and children's intelligence at 5 years of age in a cohort study in Poland. Environ Health Perspect 118(9), pp. 1326-1331.
} 


\section{Air pollution as a wicked problem}

As we see, the situation in Lesser Poland creates an opportunity to decide which philosophy of dealing with complex societal problems, in particular with air pollution, is more effective in the sense of the higher reduction of the measured level of pollution. In this regard, it is certainly a chance for an important extension of our knowledge in the area of policy science, general jurisprudence and environmental protection.

However, we believe that our study is not limited to determining practical effectiveness of certain regulations that happened to be passed in Lesser Poland, but could lead to the more general and theoretically profound conclusions. Notably, we believe that our research project has a potential for further development of a certain theory which is quite prominent among scholars interested in certain societal problems and in policy science in general. The theory of so-called wicked problems was first introduced by H. Rittel and M. Webber in 1973 and has been developed by numerous authors ever since. ${ }^{23}$

On the basis of our findings we would like to examine to what extent this theory provides adequate description of challenges that decision-makers have to face dealing with environmental issues. Although the theory of wicked problems was applied to environmental issues on many occasion, and even the very problem of air pollution has already been analyzed from the perspective the theory, ${ }^{24}$ no one has undertaken an effort to establish systematic connection between the theory of wicked problems and the perspective of legal sciences (especially the theory and sociology of law) yet. Hence, we will start with a reconstruction of the notion of wicked problem (as used in policy sciences) in order to explain it in terms of effectiveness (or various notions of effectiveness used in the field of sociology of law). The general idea is to supplement

\footnotetext{
${ }^{23}$ See Rittel H. \& Webber, M. (1973) Dilemmas in a General Theory of Planning. Policy Sciences 4(2), pp. 155169. For the general discussion of the concept of wicked problems see e.g. Conklin, J. ed. (2006) Dialogue Mapping: Building Understanding of Wicked Problems. Chichester: Wiley.

${ }^{24}$ See e.g. Lazarus, R. J. (2009) Super Wicked Problems and Climate Change: Restraining the Present to Liberate the Future. Cornell Law Review 94: 1153-1234; Levin, K. et al. (2012). Overcoming the Tragedy of Super Wicked Problems. Policy Sciences 45(2): 123- 152; Pollitt, C. (2015) Wickedness Will Not Wait: Climate Change and Public Management Research. Public Money and Management 35 (3): 181-186.
} 
ULP Law Review | Revista de Direito da ULP

Vol. 13, n. $\stackrel{1}{1}$

doi: 10.46294/ulplr13n1 ga2

the area of legal effectiveness with a taste of practical dimension. In our opinion discussions on the effectiveness of law, at least in Polish legal theory, don't adequately take into an account different types of societal problems that may be encountered in practice and may require different, sometimes very specific, solving strategies. Thus, using the concept of wicked problems we would like to propose a theoretical framework which is sounder and will substantially enrich studies on the effectiveness of law.

On the other hand, our research will mark an important development also of the theory of wicked problems, at least for two separate reasons. At the beginning, we feel that even a sheer definition of a wicked problem requires further refinement. Although in the literature the problem of air pollution is non controversially presented as wicked, we believe that there are reasons to question that. Even if we consider the classic study of Rittel and Webber, we may conclude that the problem of air pollution is well-formulated and its solutions can be measured with almost mathematical precision - which opposes the definition of wickedness, where indeterminacy of the problem is required. The problem of air pollution seems to be well defined in terms of causal relations and solutions, because, at the first glance, one could straightforwardly imagine what must be done to solve the problem and how to measure progress on that path. The network of sensors is all you may need.

On the other hand, one can easily observe a nonlinear dynamic affecting the effectiveness of the solutions to the problem of air pollution, for example through its reformulation, which is a specific feature of wicked problems. Such a reformulation might even consist in measuring NO or N02 instead of PM 2.5 or PM 10. Hence, if we are right, the theory of wicked problems and its recent developments need to be supplemented with additional content in order to ascribe wickedness to problems well defined in terms of causal relations. Without such supplementation the theory of wicked problems may be unable to fully explain wickedness in some cases.

We tentatively assume that this supplementation should account for something we called an institutional dimension of a societal problem. It is a completely different kind of wickedness which requires careful study and theoretical mapping. Suffice to say that in our opinion originally the 
theory of wicked problems does not take into consideration the dynamics of the sector of the institutions involved in solving various societal problems. ${ }^{25}$ It is because, according to our preliminary hypothesis, in case of some problems its wickedness manifests itself in peculiar inertia of institutions responsible for taking an action. These particular institutions enter into a kind of drift, refraining from action and thus protecting themselves from liability. We believe that in-depth interviews we plan to conduct, if carefully designed, will reveal a more detailed picture of this institutional dimension and verify our hypothesis.

\section{Conclusions}

Our research aims at bridging the gap between policy science and the theory and sociology of law by providing empirical material useful in the further development of both disciplines. It may also spark some general interest in the case study methodology and empirical studies among legal scholars. However, we emphasize the practical importance of the research. We expect that it will provide relevant information on the conditions and restrictions on the effectiveness of particular solutions designed to improve air quality. We believe that prohibition (command \& control) regimes appear to be more effective as a legal response to, at least, a certain type of societal problems. To put it even simpler: radically complex problems (and thus sometimes even wicked), contrary to the common intuitions, require rather simple responses instead of more sophisticated ones. Our research intends to show under what conditions and why this is happening.

That knowledge is undoubtedly important for decision-makers responsible for implementing conservation policies and will help them deal not only with the problem of air pollution, but with any problem bearing the signature of wickedness. Consequently, it will contribute to the solution of many problems, usually of great importance, by developing methods of preventing supposed institutional wickedness. We believe that the lack of sufficient interest in intuitional behavior

${ }^{25}$ For a similar conclusion see Ney, S., \& Verweij. M. (2015) Messy Institutions for Wicked Problems: How to Generate Clumsy Solutions? Environment and Planning C: Government and Policy 33 (6): 1679-1696. 
ULP Law Review | Revista de Direito da ULP

Vol. 13, n.․ 1

doi:10.46294/ulplr13n1ga2

among decision-makers constitutes a significant limitation of the effectiveness of solutions proposed. Our study, by providing practical guidance, may contribute to a better functioning of public institutions (public administration) and to higher quality of policies implemented by policymakers and other practitioners.

Finally, it is also worth emphasizing that the proposed topics of the research are consistent with the strategic objectives expressed in EU documents and the importance of research is not limited only to the case of regulations implemented over a specified part of Poland. The problem of air pollution is an important health issue and the subject of lively public debate in Europe. This debate is crucial for assessing the effectiveness of expenditure allocated to anti-smog policies under the EU structural funds. Then, our research project could be especially interesting from the point of view of an international reader interested in the issue of EU social policy and assessments of its effectiveness. The proposed research will incorporate Polish experience in introducing solutions to improve air quality into the framework of international discussions and research on this subject.

This publication is part of the research project 2019/34/E/HS5/00018 financed by the National Science Centre, Poland. 